\title{
HIVIAIDS, SURGICAL COMPLICATIONS AND CHALLENGES, THE NIGERIAN EXPERIENCE
}

\author{
O Irowa \\ Department of Surgery University of Benin Teaching Hospital Benin City
}

\section{INTRODUCTION}

Surgical complication resulting from HIVIAIDS condition stems from reduced immunity and their presentation to the surgeon is but a little different from surgical complication occurring in non infected individual. Conservation is occasionally the rule otherwise the treatment is the same as for noninfected persons.

\section{PATHOGENESIS}

HIV infection produces functional impairment of $\mathrm{CD}^{+}$lymphocytes resulting in disorders of antibodies production delayed hypersensitivity and macrophage function. This results in infective complication, haematological/ immune condition and malignancies ${ }^{1}$.

\section{SURGICAL COMPLICATIONS ${ }^{1}$}

\section{ANAL DISEASES}

- Anal warts

- Perianal sepsis

- Anorectal ulceration

- Anal neoplasms

- "Fecal incontinence

Anal warts results from human papilloma virus. This virus can promote cancer development. In these patients, they result in neoplastic changes in the anal epithelium and this has been termed anal Intraepithelial/Neoplasm (AIN). The risk of progression of this AIN to invasive and malignancy is small. Treatment for anal wart is by local excision or destruction by other local method. Podophylin is used for less extensive wart.

Perianal sepsis results from infective complication. The risk is increased for those involved in anoreceptive sex due to local trauma. Management is usually conservative with antibiotics and use of setons for those with fistula.

Anal ulcerations are due to infection, some result from herpes simplex virus infection. Acyclovir should be tried for those suspected to result from herpes virus infection while others are managed with antibiotics.

Anal neoplasms are commoner in HIV positive patient. The commonest anal neoplasms are squamous carcinoma of the anal canal, Kaposi sarcoma and non-Hodgkin's lymphoma.

Fecal incontinence this is commonly encountered in those engaged in anoreceptive sex.

\section{ACUTE ABDOMEN}

- Appendicitis - CMV, Kaposi sarcoma are common causes. Usually obstructive.

- Infective colitis: Passage of water/ mucoid bloody stools.

- Mycobacteria Avium intracellar infection - can perforate and obstruct the gut.

- Non-hodgkin's lymphoma - obstruction, perforation and $\mathrm{Gl}$ bleeding.

- Intestinal obstruction - usually from CMV.

- Perforation - usually from CMV and Kaposi sarcoma.

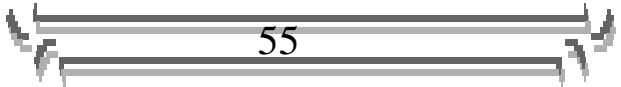


Cholangitis: Sclerosing cholangitis from cytomegalo virus infection.

Lymphoma: Presenting as abdominal swelling/pain

Splenomegally: Due to autoimmune thrombocytopenia and also from septic complication.

Hematuria: Autoimmune thrombocytopenia commonly Parotid disease.

\section{Parotid disease:}

- Saliadenitis - infection of the parotid gland presenting as swelling and pain of the gland.

- Multiple parotid cysts - disfigure the face and usually need some form of plastic reconstruction.

Thyroid swelling: CMV infection and kaposis sarcoma. Surgery usually not required.

\section{Neurological Conditions ${ }^{1}$}

- Infection - Resulting in abscess. This can be managed by antibiotics and failure to resolve will require drainage.

- Lymphoma - usually primary and present as intracranial lesion. Treatment is medical.

\section{Bone/Joint Infections}

Tuberculosis infection and bacteria infection are common in this patient and the treatment is the same for non HIVinfected individual.

\section{Chest Condition}

This is usually due to tuberculosis. Management is essentially medical except in extremes of cases were surgical intervention will be required like in lung abscess, whole lung destruction and empyema thoracis.

\section{RISK OF TRANSMISSION ${ }^{2}$}

The risk of transmission of HIV infection to the surgeon is related to:

(1) Prevalence of HIV in a population

(2) Number of procedures performed by the surgeon

(3) Length of the period of risk.

Estimated risk for an American/ European surgeon over a 30 years period is $\approx 1: 800$ chances of acquiring HIV infection and in Africa (High prevalence) $\approx 1: 4^{1}$.

Current rate of transmission from hollow needle is about $0.2 \%$ to $0.3 \%$. Risk of transmission from solid needle is about 10 fold less ${ }^{1}$.

Double gloving reduces skin contamination by 5 fold ${ }^{1}$.

NOTE: $1 \mathrm{ml}$ (of HIV infected blood) contains $\approx 50$ HIV.

$1 \mathrm{ml}$ (of HBV infected blood) contain $\approx 10^{9} \mathrm{HBV}^{1}$

\section{PREVENTION OF TRANSMISSION ${ }^{3}$}

The most important strategy of Prevention is to establish a clear indication for surgery and to avoid exposure of others unnecessarily to the risk of infection transmission.

Where an indication has been established for surgery, the surgical team wear water-proof gowns/Apron, elbow length gloves, theatre boots, face mask and, a face shield and goggles. Sharp instruments should be transferred

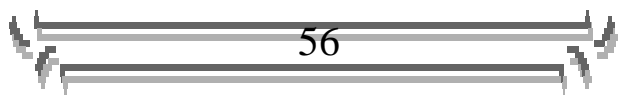


from the surgeon to the nurse in a kidney dish and vice visa.

In cases of needle stick injuries that occur during surgeries, a post exposure prophylaxis is usually taken to prevent HIV infection in the individual exposed. This usually consists of Zidovudine, Lamivudine and Indinavin.

OUR EXPERIENCE

The incidence of HIV infection following surgical procedures in our centre is not known.

For cases coming from surgery, there is a clear indication for surgery and surgery is not denied those that require it.

Preventive measures are followed to the highest standard (standard precaution).

For those exposed during surgical procedures, post exposure prophylaxis is administered.

\section{CONCLUSION}

HIV infected patients coming for surgery is common in our centre and all efforts should be made to prevent transmission of HIV infection while giving these patients due care.

\section{REFERENCES}

1. Timothy GA. Bailey and Love Short Practice of Surgery. 24 ${ }^{\text {th }}$ Edition 2004, 175-182.

2. Al-fallouji MAR Postgraduate Surgery, The candidates guide $2^{\text {nd }}$ edition, 9599.

3. Badu GA HIV infection. Principles and Practice of Surgery including Pathology in the Tropics. $3^{\text {rd }}$ edition 2000, 33-37.

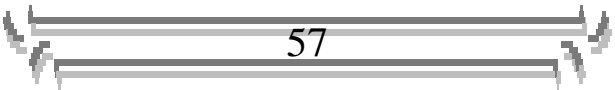

